\title{
IDENTIFICATION AND MODELLING PROCESS OF DEFINING TEMPERATURE GRADIENT IN AIRPORT PAVEMENT
}

\author{
Ervina Ahyudanari ${ }^{1,2}$, Nasir Shafiq ${ }^{1}$, Ibrahim Kamaruddin ${ }^{1}$ \\ ${ }^{1}$ Department of Civil Engineering, Universiti Teknologi Petronas, Tronoh, Malaysia \\ ${ }^{2}$ Department of Civil Engineering, Institut Teknologi Sepuluh Nopember, Indonesia \\ E-mails: ervina@ce.its.ac.id (corresponding author); nasirshafiq@petronas.com.my; \\ ibrakam@petronas.com.my
}

Received 31 October 2013; accepted 15 May 2014
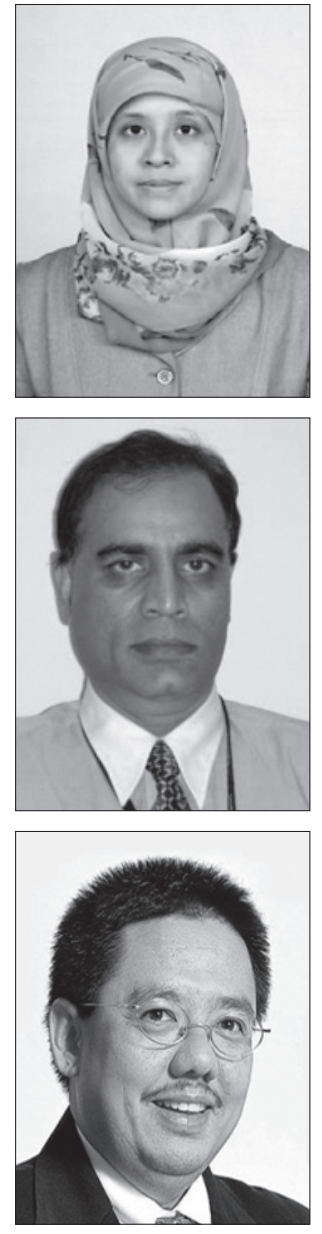

Ervina AHYUDANARI, $P h D$

Education: PhD (Airport Pavement), Universiti Teknologi PETRONAS, Malaysia; M.E. (Airport Check-in Design), University of New South Wales; Australia Bachelor in Civil Engineering, Institut Teknologi Sepuluh Nopember, Indonesia.

Affiliations and functions: 1995 to present - Institut Teknologi Sepuluh Nopember, Indonesia, Department of Civil Engineering, Associate Professor.

Research interest: airport engineering, pavement material, air transport system. Publications: author of 1 book, 3 journal papers, 11 conference papers and co-author of 9 conference papers.

\section{Nasir SHAFIQ, $D r$}

Education: PhD (Concrete Durability \& Service Life Design), University of Leeds, UK; MSc (Structural Eng.), Asian Institute of Technology, Thailand;Bachelor of Eng., NED University of Eng \& Technology, Karachi, Pakistan.

Research interest: concrete technology and structural engineering. Affiliations and functions: Universiti Teknologi PETRONAS, professor. Publications: author of 1 book and 80 papers, published in journals and conference proceedings.

\section{Ibrahim KAMARUDDIN, $D r$}

Education: PhD (Highway Eng Materials), University of Leeds, UK; MSc (Transportation/ Highway Eng), Louisiana State University, USA; BSc (Civil Eng), University of Sussex, UK. Research interest: highway and transportation engineering. Affiliations and functions: Universiti Teknologi PETRONAS, associate professor. Publications: author of 6 journal papers and 50 papers in conference proceedings. 
loading. The thermal cyclic load follows the aircraft schedule pattern. The pavement temperature receives the thermal cyclic load of the sinusoid of solar radiation. The results indicate that the temperature of the pavement is increased and pavement temperature rises by $35^{\circ} \mathrm{C}$. However, after 60 seconds the remaining temperature of the pavement layer decreases to the initial temperature, which is caused by solar radiation.

Keywords: airport pavement; temperature gradient; modelling process.

\section{Introduction}

Thermal load induces airport pavement in three different ways and magnitudes. These three types of thermal load are solar radiation, friction between the tire and pavement surface, and jet exhaust produced by jet aircraft engines. The solar and frictional heat is a common thermal load received by pavements. The intriguing part is the presence of thermal load resulting from jet exhaust ejected from jet engines. There is no accessible publication related to this type of thermal load. However, the effect of jet exhaust is present in ASTM D5340-03 Section X1.7 (ASTM 2004):

Jet blast erosion causes darkened areas on the pavement surface where bituminous binder has been burned or carbonized. Localized burned areas may vary in depth up to approximately $1 / 2$ inch $(13 \mathrm{~mm})$.

Based on this statement, this research provides an enhanced discussion on jet engine exhaust. The rational issue is that the depth of the localized burned pavement may become the cause of Foreign Object Debris (FOD) since the nominal maximum aggregate size (NMAS) for airfield pavement is $8-11 \mathrm{~mm}$ in Germany, $8 \mathrm{~mm}$ in Norway, and $13-15 \mathrm{~mm}$ in China (Prowell et al. 2007). FOD is a danger to aircraft engines.

The jet engine exhaust that consists of temperature and velocity for drag and lift during the take-off process is essential to an aircraft. The blast temperature has a smaller affected area in comparison with the area that receives the effect of the blast velocity. Each jet engine has its own patterns of temperature and velocity at various levels of power setting. There are three different levels of power setting that show variation in blast temperature and velocity as produced by the jet engine exhaust, namely, idle power, break away and take-off power. In this research, the take-off power is considered. The distance between the bottom part of the jet engine and the pavement surface varies from $50-70 \mathrm{~cm}$. However, due to the vast area covered by the jet exhaust effect, the jet blast may diffuse into the pavement layers.

The objective of this paper is to provide a synthesis of the process of defining the temperature gradient at a certain depth of the airport pavement structure. This objective is a reflection of the hypothesis of this research, which indicates that a certain condition may cause the effect of jet blast as stated in ASTM. The expected results should reveal the potential of the thermal load of the jet exhaust to affect the flow of bitumen on the pavement surface. The analysis involves the assessment of the schedule of aircraft movement and the intensity of solar heat during a selected period. The period under analysis is the period during the peak hours of airport operation and during midday when the intensity of the solar heat is at the maximum.

To accomplish the objective of this study, the investigation was carried out in four stages. The stages are: gap analysis, evaluation of airport pavement structure, determination of the load path and magnitudes and defining the temperature gradient in the airport pavement. The aim of the gap analysis is to discover all research areas that have a relation to airport pavement and also attempts to observe any area of research that has not been discussed in detail. The assumption is that issues related to the correlation between jet exhaust and pavement surface have not been discussed widely. The evaluation of the airport pavement structure is carried out in order to assess the condition of the pavement structure, based on the field data. The assessment results are used to support the gap analysis result in demonstrating the presence of the effect of jet exhaust on pavement surface. The determination of loading paths and magnitudes allows identifying the part of the runway that receives higher load intensity. The results of this stage become entry values for the following step. The last stage is defining the temperature gradient. In this stage, the periods of load time and load play a role in determining the temperature gradient of the airport pavement.

The organization of this paper follows the four stages to demonstrate the process conducted to obtain the temperature gradient of the airport pavement. The presentation is a summary of each of the steps conducted in this research project. The results of a model development of the pavement temperature gradient are briefly presented and discussed.

\section{Gap analysis}

An investigation related to airport pavement requires considering four elements that are linked and developing one vast area of research. The elements involved are: the advancement of technology in the aircraft industry, development of airport pavement structure design, discovery of new pavement material and development of new technology in the airport pavement maintenance system. 
The aircraft industry is continuously developing in size and gross weight to meet the increasing demand in air transport (How air... 2003). This development requires a novel design of landing gear configuration. The National Airport Pavement Test Facility (NAPTF) in New Jersey, USA, conducted research related to discovering the different effects of the new landing gear configuration (Gopalakrishnan 2004, 2008). To consider the issue related to new large aircraft (NLA), some institutions conducted research to discover a new design or an additive on pavement material. Cooley et al. introduced the Superpave mix design for airfield pavement (Cooley et al. 2007). A. A. Abdo et al. suggested the dynamic modulus as the considered parameter to determine the performance of hot mix asphalt (HMA) (Abdo et al. 2009). The method of compaction of the mix design mixture also influences the quality of airport pavement (Rushing 2009). The adequate structure also needs to be maintained regularly. The Airport Pavement Management Subcommittee of the Transportation Research Board has published guidance material for developing the Airport Pavement Management System (APMS) in some airports (Tighe, Covalt 2008). The APMS require maintaining a database in order to select an appropriate maintenance strategy. Another consideration was the development of information technology as a single tool to assist the airport operator in making the decision (Huang et al. 2007). Another effort is to provide a non destructive testing (NDT) method to evaluate the pavement roughness using a Boeing simulator (Larkin, Hayhoe 2009). This NDT preserves the pavement structure from being tested in the laboratory. The simulated result may help the airport manager to maintain the roughness of the pavement, especially runway area and to avoid the unacceptable shocking effect on the aircraft structure.

The correlation of these four elements can be illustrated as a circle with four quadrants. Each quadrant represents one element. These four quadrants give a wideangle view of the relative position of the research in the four elements, which are parts of the airport pavement research area. This illustration gives an idea about the position of the effect of jet exhaust on airport pavement in a wide research area.

Figure 1 shows the four elements in the airport pavement research area. The wings represent the sub element in each quadrant. The arrows at the centre of the circle illustrate the relationships among the quadrants. For example, the development in aircraft technology is the reason to have an improvement in the design of airport pavement structure. The design of the pavement structure requires the advance of research for discovering reliable material. The high quality of the pavement structure needs regular maintenance to maintain the serviceability and flight safety.

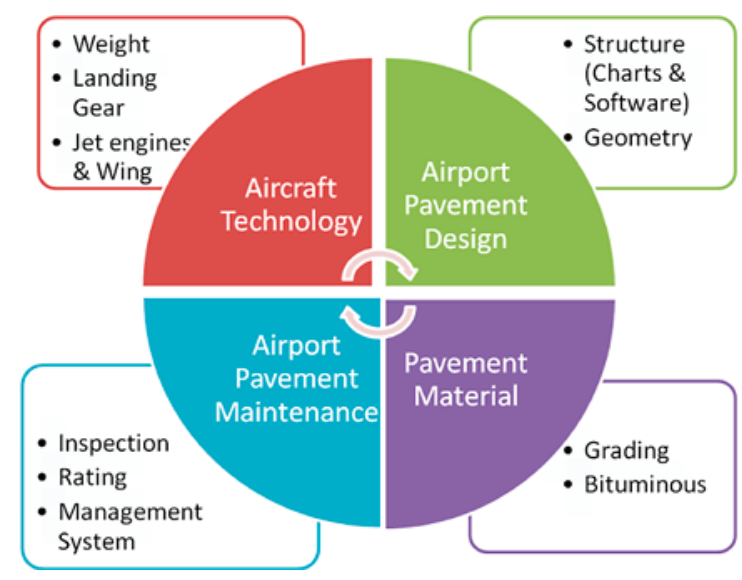

Fig. 1. The four quadrants of the airport pavement research area

Figure 1 presents the summary of the literature review. The figure shows that one part of aircraft technology has not been included in any quadrant. This part is the jet engine. The wings of the aircraft have been included in the gross weight of an aircraft and do not have a direct impact on the pavement. The following discussion indicates some parts of the quadrants related to the jet exhaust effect that may not have been considered yet.

- Based on the assessment of some reports, journals, manuals and available procedures related to airport pavement, there are a number of gaps, which are interesting grounds to be investigated. The following list includes the salient features that may be treated as gaps for future research.

- The increasing gross weight of aircraft requires higher thrust, which produces a greater velocity of the jet engine exhaust. The pavement surface needs a design that is able to receive the expected jet exhaust.

- Airport pavement design, both charts and computer-based forms, mainly focus on structural design. It would be possible to develop a similar chart to predict the performance of the pavement surface.

- The improvement of the performance of airport pavement material supports the design of the pavement structure. Although some modifications have been made in gradation selection and bituminous characteristics, there is doubt about the involvement of the jet engine exhaust effect in the analysis of the performance of those materials.

- The manual and procedures of airport pavement inspection include both surface and structural defects. The jet blast erosion that corresponds to traffic is not considered in the pavement design process. The design manual contains no surface defects. This is related to the second point of this gap list. 
While conducting research and development some institutions and researchers mainly focus on designing well-built airport pavement structures, as shown in the elements discussed above. Research on airport pavement structure covers the selection of both the method and material, which are associated with the development in aircraft technologies. However, although jet engines are associated with aircraft improvement, the effect of jet engine exhaust is not fully considered. Since the jet blast effect is more related to surface defects, it is considered the research area of maintenance management.

Currently, the pavement maintenance management group of research is improving the methods of inspection and rating of the pavement performance and other non-structural problems. The effect of jet engine exhaust may not be deemed relevant since the rehabilitation process can be combined with other types of surface defects. On the other hand, it is interesting to determine the contribution of jet engine exhaust to reducing pavement performance.

The presented gap analysis indicates that an investigation of the effect of jet engine exhaust may reveal additional knowledge about airport pavement behaviour. This knowledge is expected to become the basis for further research in order to preserve airport pavement performance.

\section{Assessment of the pavement structure}

The second stage of this research is the assessment of pavement structure. The objective of this stage is to evaluate the adequacy of the selected airport pavement structure. For this purpose, 13 airports under management of PT Angkasa Pura 1, Indonesia, provided the related information. The data required for this evaluation is aircraft movements (traffic), pavement structure, and pavement maintenance history.

The pavement evaluation of the 13 selected airports is expected to support the hypothesis related to the presence of the effect of jet engine exhaust in the field. The

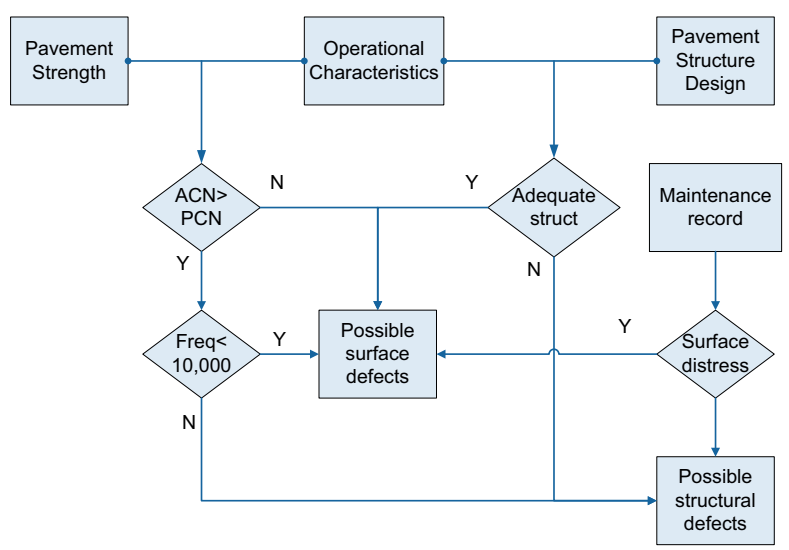

Fig. 2. Methodology of the analysis of pavement condition (Ahyudanari et al. 2010) previous gap analysis stage, gave strong support from the research literature point of view and the completion of the second stage may provide strong support for the hypothesis.

The assessment of the airport pavement structure comprises three different stages (Ahyudanari et al. 2010): the evaluation of the structural adequacy, pavement strength and pavement maintenance record. The relationship between these evaluations is presented in figure 2.

\section{Assessment of the pavement structure}

For the assessment of the pavement structure a design curve published by FAA was adopted (FAA 1995). The variables in the FAA designed curve (FAA 1995) represent an interactive system between the airport pavement and the aircraft operating on it. The variables that must be addressed in the pavement assessment process include: the CBR value, the existing pavement thickness, the annual departure, the landing gear type and the gross weight of the aircraft. The analysis and discussion in this section will cover these variables to reveal the condition of the pavement structure in the airports under analysis.

The code attributed to the 13 selected airports follows the IATA (International Air Transport Association) code. For example, SUB stands for Surabaya, DPS indicates Denpasar, etc.

Figure 3 shows the results of 12 airports under evaluation. These results are obtained from the design curve of the FAA. The figure illustrates that most of the existing pavement thickness (based on data collected in the year 2007) exceeds the required pavement thickness for the traffic in the year 2007. The pavement thickness of three airports is lower than required; these are AMQ, DPS and MDC. SUB has been excluded from this figure since the annual departure and the existing pavement thickness of SUB exceed the available graph. The maximum value for annual departure is 25.000 and 50 for pavement thickness, which is lower than the annual departure and

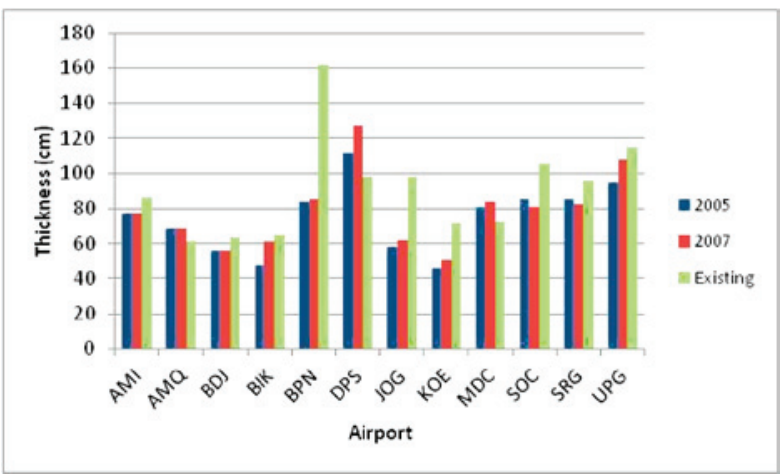

Fig. 3. A comparison of the required pavement thickness based on traffic in 2005, 2007; and the existing (2009) pavement thickness 
pavement thickness of SUB. In addition, SUB serves B-777. Neither the design curve nor FAARFIELD (Federal Aviation Administration Rigid and Flexible Iterative Elastic Layered Design) (FAA 2009) facilitate to determine the required pavement thickness for B-777. FAARFIELD is another pavement design program published by FAA to complete the design charts.

From the analysis of the three variables, i.e. the CBR value, annual departure and landing gear, it can be concluded that the load received is lower than the predicted load. This conclusion is a general one since there is no further analysis related to the variable involved. The pavement condition is afterwards evaluated through the pavement strength method.

\section{Evaluation of pavement strength}

The aim of the evaluation of pavement strength is to identify whether the pavement in the selected airports requires earlier maintenance due to excessive load or other causes. Pavement strength is the load carrying capacity of a pavement under unrestricted operation (FAA 2006). Although the structure of the pavement has to meet the traffic requirements, there is a possibility that the operated aircraft exceed the standard operational requirements.

For determining airport pavement strength, ICAO adopted the Aircraft Classification Number - Pavement Classification Number (ACN-PCN) method (ICAO 1999) to express the effect of individual aircraft on different pavement structures. The ACN-PCN is a single unique number that represents the strength of the pavement.

The evaluation in this paper only presents the evaluation results for SUB. The SUB airport has the highest percentage of traffic distribution among the other 12 airports under PT Angkasa Pura 1 management. It serviced $25 \%$ of the total traffic in the year 2006. The evaluation was conducted applying three different approaches. The adopted methodologies are Transport Canada, aircraft manufacturer, and COMFAA, computer software provided by FAA (FAA 2006). The results indicate that some aircraft were exceeding the available pavement strength.

The requirement of permissible higher ACN value without any restriction in operation is only $5 \%$ of the PCN (FAA 2006). Figure 4 illustrates that these aircraft are exceeding PCN by more than $5 \%$. As required by ICAO all aircraft that surpass the PCN of corresponding airport by more than 10\% (FAA 2006), are required to undertake an overload analysis. Such aircraft operate on the pavement for less than $1 \%$ of the time annually. Although the ACNs are much higher than the $10 \%$ as required, the frequency of such movements is very low. The requirements for the annual number of overload traffic are to be applied in cases when more than $5 \%$ of the total annual airplane traffic is exceeded. Therefore, it is not necessary to conduct the overload analysis.

The aircraft with an ACN exceeding PCN need further analysis related not to the pavement structure, but to other significant causes associated with the surface condition. The investigation will be focused on the jet exhaust produced by these aircraft.

\section{Pavement maintenance history}

The aim of the evaluation of pavement maintenance history is to draw a picture of the frequency of pavement maintenance, and maintenance or rehabilitation activities conducted on the selected airports. The maintenance frequency is related to the traffic pattern. The selected airports, as a group, undergo greater load than initially deemed. The increasing traffic trend needs to be evaluated in conjunction with the frequency of pavement maintenance. Therefore, it is expected that the result of this evaluation will form a supporting statement for the previous two evaluation results regarding the performance of the pavements in the selected airports.

The reported overlay for each airport is caused by a functional defect and not a structural defect. This statement was supported by the results of the two previous evaluations. The average thickness of the overlay followed the requirements for minimum thickness for the corresponding CBR value.

The SUB has a different report model of the pavement maintenance record. The length of overlays indicated that the overlay only applied to certain areas of the runway. There is no record explaining the reason for the overlays up to the year 2005. The latest record reported the pavement distress type. All records showed that the pavement deterioration was limited to functional defects, such as ravelling, skid resistance and rubber deposit. Ravelling, skid resistance and rubber deposit are associated with the temperature effects. Based on these records, only the SUB is included in further analysis. The evaluation also showed that for the airport with less traffic, the airport authorities conducted overlay due to the environmental effect.

\section{Summary of all the evaluations}

The evaluation conducted covered the evaluation of the pavement structure, pavement strength, and pavement maintenance history. The results established that the pavement structure of the selected airports had an adequate thickness to meet the design life. The pavement strength assessment also exhibits that the pavement of the selected airports does not have an overload condition yet. Lastly, the evaluation of pavement maintenance history has been carried out and the results indicate that the pavement distress that occurred was related to the pavement surface defects. 
The three evaluations of the pavement condition confirm that the design of the pavement structure meets the requirements and includes almost all aspects in the quadrant in figure 1. One aspect of aircraft technology, namely the jet engines that produce heat, has not been encountered yet. This variable may possibly cause an effect on pavement surfaces. The main issue is how much the heat of the jet exhaust affects the pavement surface.

\section{Determination of loading path and magnitude}

This chapter presents the process for determining the part of the runway that receives a higher load intensity. The aim of this presentation is to illustrate the load types and magnitudes that will be used to predict the pavement surface condition after a certain period of receiving a load combination.

The loading area affected by aircraft weight is easier to identify than the loading area affected by the jet exhaust. The wheel track of an aircraft and its TOD are considered as the load path. This load path is different from the heat load due to the load distribution of the jet engine exhaust. The heat load spreads in a wider area. The area of spreading differs from one engine to another. The number and the position of the engines also determine the area of the heat load. For an aircraft with four engines, the heated area covers the entire width of the runway.

The load magnitude of aircraft weight is distributed through the wheels with a certain tire pressure. The wheel load and tire pressure determine the tire contact area. This contact area defines the load magnitude that is represented by the loading time and the load itself.

The distribution of the tire contact area, as presented in figure 4, reveals a linear relationship with increasing wheel load. The figure also infers that the tire pressure for operated aircraft is maintained according to the aircraft load to avoid increasing the possibility of rutting. This is assumed from the use of wide base tires that cause less fatigue damage (Al-qadi, Wang 2009).

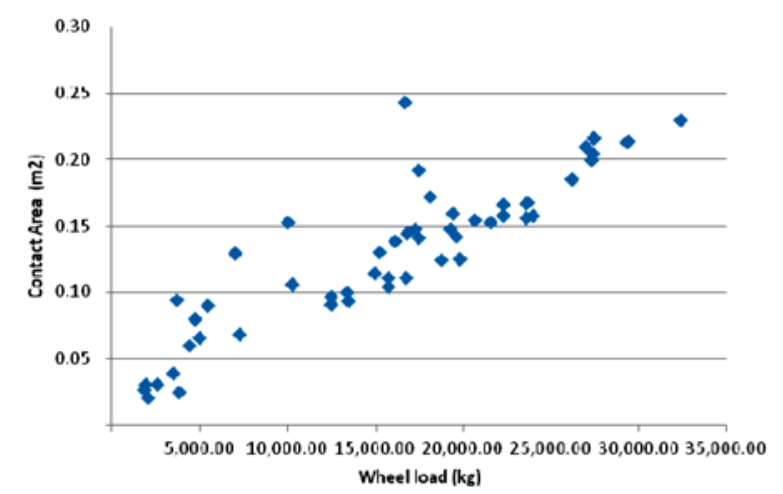

Fig. 4. The distribution of the tire contact area
Due to aircraft weight, the load is applied when the pavement receives the heat load from solar radiation, equal to $250 \mathrm{~W} / \mathrm{m}^{2}$. The solar radiation is a quasi steady load. The moving aircraft add a transient load composed of two combination loads, i.e. aircraft weight and the jet exhaust load in the range from 13.000 to $380.000 \mathrm{~W} / \mathrm{m}^{2}$. The heat load due to friction is excluded, since it does not add a significant heat load. The load combination is designed as an entry load in the model presented in the next section.

\section{Defining the temperature gradient}

The results presented in the two previous chapters suggest that jet engine exhaust may contribute to airport pavement deterioration. This hypothesis requires a model to determine the significance of the effect of jet exhaust on the pavement surface. The model postulated necessitates an elaboration of the heat transfer process that affects the characteristics of pavement material. The problem related to the temperature on the pavement is that there are two thermal load sources involved in the temperature generation process, namely solar radiation and heat produced by the jet engine exhaust.

The development of the model presented in this chapter encapsulates two separate models for heat sources to delineate the magnitude of each heat source. The rational motive for the model separation is the fact that the two heat sources have different periods of occurrences. The model separation pertains to the preliminary analysis done prior to the model combination. Each model needs to be scrutinized in order to avoid arduous model compounding. It is deemed to move towards model simplification instead of an insurmountable model.

The methodology of the analysis incorporates a routine program for the selected period. A set sequence of steps is employed to determine the thermal penetration depth and its magnitude within pavement layers. A brief methodology is provided in figure 5 .

There are two different loading characteristics in this analysis. The solar radiation has a different magnitude of insulation due to the angle of incidence. Maximum incidence occurs when the hour angle shows $0^{\circ}$, which means during midday. In contrast, the heat produced by the jet engines reaches maximum intensity during the peak hour of traffic. The peak hour in the SUB occurred in the periods 07:00-08:00 and 10:00-11:00 with 23 departing aircraft in each period. Based on this condition, the temperature gradient is determined for the three different periods, as mentioned. The formula in this case is expressed in a dimensionless form as follows (Hagen 1999):

$$
\frac{T-T_{0}}{T_{i}-T_{0}}=\operatorname{erf}\left(\frac{x}{2 \sqrt{\alpha t}}\right) .
$$


Here $T_{i}$ indicates the initial temperature. The function erf is called the error function, which is defined by the integral that arises in probability theory (Hagen 1999). The error function eliminates the occurrence of errors due to the adoption of a sigmoid shape in the analysis.

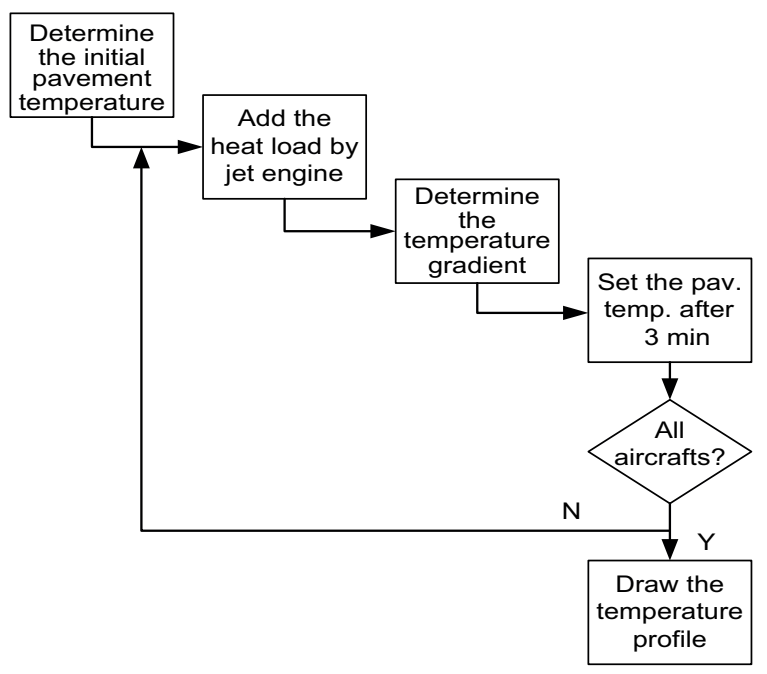

Fig. 5. Methodology of the analysis

The incremental temperature growth of the pavement surface does not occur at the same time as the intermittent aircraft movements. The time of the departing aircraft has to be plotted according to the corresponding period of solar heat. Two aircraft that take off subsequently are separated by 3 minutes. This separation time is the time required for the jet vortex to disperse (Gerz 1997), which may be form 1.5 to 3 minutes depending on the atmospheric condition.

The temperature gradient for each of the selected loading periods has been established. An essential step is designing an algorithm, which would correspond to updating the temperature gradient profile due to the load pulse of the jet exhaust. In determining the heat transfer resulting from a very short jet load pulse, it is assumed that no heat is lost from the surface by convection or radiation. The following formula is applied in this case (Hagen 1999):

$$
T-T_{i}=\frac{E}{\left(\rho C_{p} \sqrt{\pi \alpha t}\right.} \exp \left(\frac{-x^{2}}{4 \alpha t}\right) .
$$

The unit for $E$ is $\mathrm{J} / \mathrm{m}^{2}$ in the SI system. The unit for the thermal load due to the jet exhaust is $\mathrm{W} / \mathrm{m}^{2}$. 1 Joule = 1 Watt second (Sachdeva 2009); therefore, the load pulse of the jet exhaust is multiplied by the period of its occurrence.

A diagram of the increasing temperature of the pavement surface is presented in figure 6. Figure illustrates the fluctuation of the surface temperature in the period form 07:00 to 08:00 AM. The jet flux of B737 raised the surface temperature by around $6{ }^{\circ} \mathrm{C}$ (a) and dropped by around $5{ }^{\circ} \mathrm{C}$ (b) in the next minute. After reaching this state, the temperature gradually decreases and is close to the initial temperature of the solar flux. The time required to recover to the initial temperature depends on the interval between two consecutive flights. The last flight at this period is at 7.55. Figure shows that the effect of the jet flux is only about $32{ }^{\circ} \mathrm{C}$ above the pavement temperature due to the solar flux at 8:00 AM.

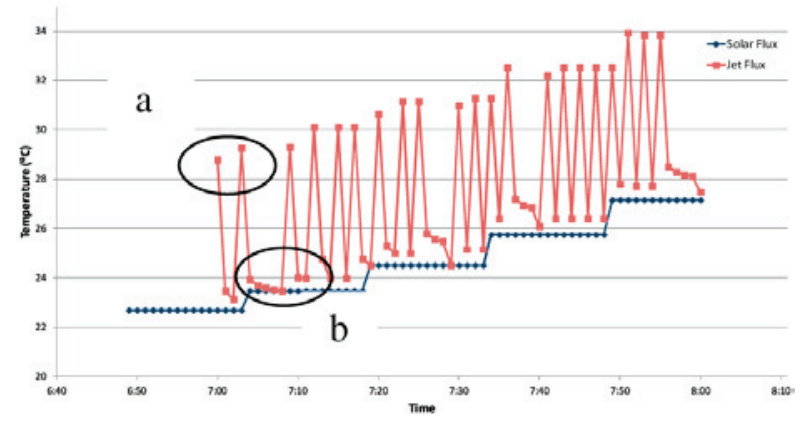

Fig. 6. The profile of temperature fluctuation on the pavement surface

The profile of the pavement underneath the surface is not as varied as the surface profile. A diagram of the temperature gradient at $x \mathrm{~cm}$ depth is presented in figure 7. The legend that indicates a number from 1 to 23 corresponds to the flight sequence in the period from 07:00 to 08:00 AM. The temperature gradient is high at the first centimetre below the surface. This is relevant to the thermal properties of asphalt concrete. The diffusivity of the pavement material is very low; therefore, the effect of the very short heat flux only affects the first centimetre of the surface.

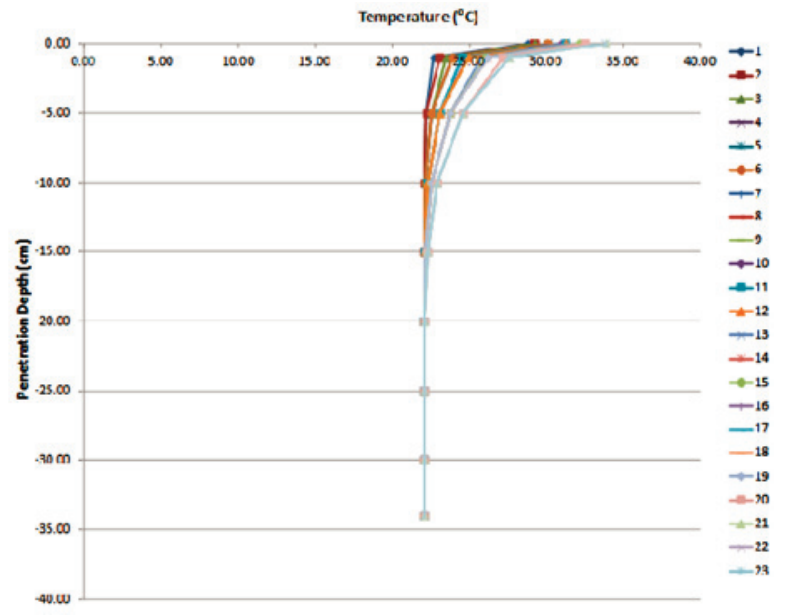

Fig. 7. The temperature gradients at $x \mathrm{~cm}$ after receiving the jet flux in the period from 07:00 to 08:00 AM

\section{Conclusions}

The process of defining the temperature gradient of airport pavement has been presented. The process started by conducting a comprehensive literature research to ascertain that research in order o discovers the effect of 
jet exhaust on airport pavement is worth considering. The proposed research also requires the results about the field condition. The field condition was obtained through three different stages of evaluation of airport pavement condition. The results strongly support the idea that jet exhaust affects the pavement surface. Determining the loading path and magnitude of each load type that needs to be carried continues the process. The loading characteristics also need to be considered in order to have a strong argument in the simplified analysis.

\section{Acknowledgements}

This research was supported by the Universiti Teknologi Petronas. The data of this research were provided by PT Angkasa Pura 1 and the Directorate General of Air Communication - the Ministry of Transportation, Indonesia.

\section{References}

Abdo, A. A.; Bayomy, F.; Nielsen, R., et al. 2009. Prediction of the dynamic modulus of superpave mixes, in Bearing Capacity of Roads, Railways and Airfields. $8^{\text {th }}$ International Conference (BCR2A'09), June 29 - July 2, 2009, Champaign, Illinois. Taylor \& Francis Group, 305-314.

Ahyudanari, E.; Shafiq, N.; Kamaruddin, L. 2010. An alternative method in evaluation approach of airport pavement performance, in Proceeding of Malaysian Universities Transportation Research Forum and Conferences [online] [cited 27 April 2013], 2010: 1-10. Available from Internet: http://www.uniten.edu.my/newhome/content_list.asp?contentID $=4234$

Al-qadi, I. L.; Wang, H. 2009. Evaluation of Pavement Damage Due to New Tire Design. Security [online], [cited 27 April 2013], 1-74. Available from Internet: http://ict.illinois.edu/ Publications/report_files/FHWA-ICT-09-048.pdf

ASTM. 2004. ASTM D 5340-03: Standard Test Method for Airport Pavement Condition Index Surveys. December 2. ASTM International.

Cooley, L. A.; Prowll B.; Ahlrich, R. 2007. Implementation of superpave mix design for airfield pavements, AAPTP Project 04-03. Airfield Asphalt Pavement Technology Program. Ridgeland, Mississippi. 21 p.

FAA. 1995. Advisory Circular: AC 150/5320-6D: Airport Pavement Design and Evaluation. Facilities. Federal Aviation Administration, U.S. Department of Transportation.

FAA. 2006. Advisory Circular: AC 150/5335-5A: Standardized Method of Reporting Airport Pavement Strength - PCN Evaluation. D. L. Bennet (Ed.). Federal Aviation Administration, U.S. Department of Transportation. 1-63.

FAA. 2009. Advisory Circular: AC 150/5320-6E: Airport Pavement Design and Evaluation. Federal Aviation Administration, U.S. Department of Transportation.

Gerz, T. 1997. Wingtip vortices and exhaust jets during the jet regime of aircraft wakes, Aerospace Science and Technology 1(7) 463-474. http://dx.doi.org/10.1016/S1270-9638(97)90008-0

Gopalakrishnan, K. 2004. Performance Analysis of Airport Flexible Pavements Subjected to New Generation Aircraft. University of Illinois at Urbana-Champaign.
Gopalakrishnan, K. 2008. Predicting capacities of runways serving new large aircraft, Transport 23(1): 44-50. http://dx.doi.org/10.3846/1648.4142-2008.23.44-50

Hagen, K. D. 1999. Heat Transfer with Application. Helba, S. (Ed.). Upper Saddle River, New Jersey: Prentice-Hall, Inc.

How air traffic controllers keep airplanes apart. Livingstone Enterprises [online], [cited 27 April 2013]. Available from Internet: http://glivingstone.com/separation.html

Huang, S. M.; Chang, C. C.; Hsu, P. Y., et al. 2007. Application of information management system approach in airport pavement maintenance strategy selection, Journal of CCIT36 [online], [cited 27 April 2013]. Available from Internet: http://jccit.ccit.ndu.edu.tw/ezfiles/7/1007/ img/27/3(No.243).pdf

ICAO. 1999. Annex I4: Aerodromes. $3^{\text {rd }}$ ed. 1. 205 Ottawa: International Civil Aviation Organization.

Larkin, A.; Hayhoe, G. F. 2009. Federal Aviation Administration airport pavement management and airport pavement roughness evaluation, in NDTE'09, Non-Destructive Testing in Civil Engineering. Nantes, France.

Prowell, B.; Hurley, G. C.; Watson, D. E., et al. 2007. Evaluation of Stone Matrix Asphalt (SMA) for Airfield Pavements. Asphalt.

Rushing, J. F. 2009. Development of Criteria for using The Superpave Gyratory Compactor to Design Airport Pavement Mixtures. Mississippi State University.

Sachdeva, R. C. 2009. Fundamentals of Engineering Heat and Mass Transfer. New Age Science Limited.

Tighe, S.; Covalt, M. 2008. Transportation Research Circular No E-C127: Implementation of an Airport Pavement Management System [online], [cited 27 April 2013]. Available from Internet: http://onlinepubs.trb.org/onlinepubs/circulars/ec127.pdf 